Acta Protozool. (2019) 58: 217-233

www.ejournals.eu/Acta-Protozoologica

doi:10.4467/16890027AP.19.019.12021

PROTOZOOLOGICA

\title{
Growth Rate Modulation Enables Coexistence in a Competitive Exclusion Scenario Between Microbial Eukaryotes
}

\author{
Giulia Magri RIBEIROa, Paulo Inácio PRADO ${ }^{\mathrm{b}}$, Renato Mendes COUTINHO ${ }^{\mathrm{c}}$, Marina Costa \\ RILLO $^{\mathrm{d}}$, Samuel PEREIRA Junior ${ }^{\mathrm{a}}$, Alfredo L. PORFÍRIO-SOUSA ${ }^{\mathrm{a}}$, Daniel J. G. LAHR ${ }^{\mathrm{a}}$ \\ a Departamento de Zoologia, Instituto de Biociêcncias, Universidade de São Paulo, Cidade Universitária, São Paulo, Brazil \\ ${ }^{\mathrm{b}}$ LAGE do Departamento de Ecologia, Instituto de Biociências, Universidade de São Paulo, Cidade Universitária, São Paulo, Brazil \\ ${ }^{\mathrm{c}}$ Centro de Matemática, Computação e Cognição (CMCC), Universidade Federal do ABC, Av. dos Estados, 5001, Santo André, \\ Brazil \\ d Ocean and Earth Science, National Oceanography Centre Southampton, University of Southampton Waterfront Campus, \\ Southampton, UK
}

\begin{abstract}
Coexistence usually are exceeding the explicable rate by competitive exclusion principle. Since the pioneer Gause, many studies have used protist microcosm systems to study competitive exclusion. We explored a two-species system with the testate-amoebae: (Arcella intermedia and Pyxidicula operculata), where competitive exclusion is expected to occur. We determined their growth curves individually and under competitive interaction. We used a state-space model to represent system dynamics and calculated posterior population sizes simulating competition dynamics. Contrarily to our expectation, Arcella and Pyxidicula showed similar growth rates (1.37 and 1.46 days ${ }^{-1}$ respectively) and only different carrying capacity (1,997 and 25,108 cells $\mathrm{cm}^{-2}$ respectively). The maximum number of cells of both species when growing in competition was much lower if compared to the monospecific cultures (in average, $73 \%$ and $80 \%$ less for Arcella and $P y x$ idicula respectively). However, our competition experiments always resulted in coexistence. According to the models, the drop in growth rates and stochasticity mainly explains our coexistence results. We propose that a context of ephemeral resources can explain these results. Additionally, we propose generating factors of stochasticity as intraspecific variation, small population effects, toxicity of waste products and influence of the bacterial community.
\end{abstract}

Keywords: competition, protists, testate-amoeba, experimental ecology, coexistence, microcosm.

\section{INTRODUCTION}

The mechanism behind species turnover in the environment remains subject of much debate (Bastolla et al. 2005, Fronhofer et al. 2015). Under realistic con-

Address for correspondence: Daniel J. G. Lahr, Rua do Matão, Travessa 14, 101, Cidade, São Paulo, SP, Brazil, 05588-090, E-mail: dlahr@ib.usp.br. ditions, environmental constraints prevent organisms from multiplying endlessly. The differential response to such constraints as well as environmental heterogeneity promotes both coexistence and turnover of lineages in space and time (Amarasekare 2000, Chesson 2000). The environmental limitation is typically the exhaustion of a resource, but it can also be the accumulation of harmful metabolites in the environment (Pianka 2011). Coexistence is still a central topic in ecology because 
when ecologically similar species are together in mixed population settings, species that are more efficient at exploiting the resource are expected to exclude other less efficient species, a process known as competitive exclusion (Bastolla et al. 2005, Gause 1934). Georgii Gause pioneered the empirical tests of this idea, initially investigating predator-prey dynamics, but later focusing on competition experiments as well (Gause 1934). Since then, many studies have used protist microcosm systems to study competitive exclusion, focusing on the effects of species traits (Cadotte 2007, Hart et al. 2016, Maachler and Altermatt 2012), phylogenetic relatedness (Violle et al. 2011), spatial dynamics (Carrara et al. 2012), environmental disturbance (Altermatt et al. 2011, Haddad et al. 2008), trade-offs (Cadotte 2007, Cadotte et al. 2006, Violle et al. 2010), environmental changes (Jeremy et al. 2001, Petchey et al. 1999), invasion dynamics (Giometto et al. 2014, Maachler and Altermatt 2012) and scaling laws in ecology (Fenchel 1974, Giometto et al. 2013). However, usually these experiments have coexistence exceeding the expected and explicable number based on competition theory.

For over 90 years, competition was seen as a deterministic and oversimplified theoretical process (Pianka 2011). The basic competition models, Lotka-Volterra (LV) equations (Lotka 1920, Volterra 1926), are a modification of the Verhulst-Pearl logistic equation (Verhulst 1845), sharing its assumptions and differing only by adding a competition factor multiplying the densities of each species. This simple model is still a useful framework to describe the outcomes of competition as either the exclusion of one species, or coexistence of both, which may or may not depend on the initial species abundances. One of the advantages of simple models is that they can "fail in informative ways" (Rosindell et al. 2011). A variety of factors not included in the Lotka-Volterra basic model can affect the outcome of competitive interactions. Decisive factors of competition are thought to be either rapid utilization of nutritional resources and resistance to waste products (Gause 1934, Kayser 1979). In addition, environmental change, demographic fluctuations, disease, and chance are a few other possible factors. Our aim was to investigate some of those factors in an experimental setting very similar those used by Gause, using an enhanced version of the classical Lotka-Volterra model.

We explored a two-species system within the testate-amoebae lineage Arcellinida (shelled amoebae). Arcellinida lineages are conspicuous, abundant and ubiquitous in aquatic environments across the globe
(Kosakyan et al. 2016). In this work we wanted to investigate the competitive ability of two representatives of Arcellinida lineage: Arcella intermedia and Pyxidicula operculata (Fig. 1) when grown in a shortterm batch experiment. These two species co-inhabit the same fresh-water environments, especially roots of floating aquatic plants, and both feed preferably on bacteria (Meisterfeld 2002). Thus they have similar ecological requirements, but have very distinct cellular sizes: A. intermedia diameter is, on average, ten times larger than $P$. operculata diameter $(5.7 \mu \mathrm{m}$ as opposed to $5.3 \mu \mathrm{m}$, Fig. 1). The literature claim that in microbial eukaryotes, as in metazoa, the size of organisms is a fundamental property that influences individual-level metabolism, density, growth rate, community structure and ecosystem functioning (DeLong et al. 2010, HueteOrtega et al. 2012, Kempes et al. 2012). In that way, smaller individuals with lower requirements would attain higher abundances than larger individuals. Both species were set in a batch microcosm experimental approach, in which conditions are initially defined. The system evolves continuously during the experiment. During the period where nutrients are in excess, these systems behave essentially as enrichment cultures in which strong selection occurs favoring organisms with a higher maximum specific growth rate. Once nutrients are depleted survival becomes the main adaptive factor. Here, we designed experimental conditions where competitive exclusion is expected to occur. We first determined their individual growth curves and then measured the growth curves of each species under competitive interaction. Our null-hypothesis was that the smaller species ( $P$. operculata) would present a faster growth response, and eventually excludes the larger species (A. intermedia).

\section{MATERIALS AND METHODS}

\section{Biological material and culturing}

We isolated two species of testate amoebae (A. intermedia and $P$. operculata). One individual of each species was isolated from the same artificial lake within São Paulo city, Brazil (University of São Paulo campus, coordinates lat - 23.565720, long -46.730512). A. intermedia strain is isolated since 2013 and P. operculata since 2015. The single initial individual, in each case, was used to generate clonal, mono-eukaryotic, stock cultures. Both the single-species and the competition experiments were inoculated with clones from these stock cultures. We performed growth experiments in 2015. The cultures were maintained at $24{ }^{\circ} \mathrm{C}$ in $25 \mathrm{ml}$ culture flasks with 


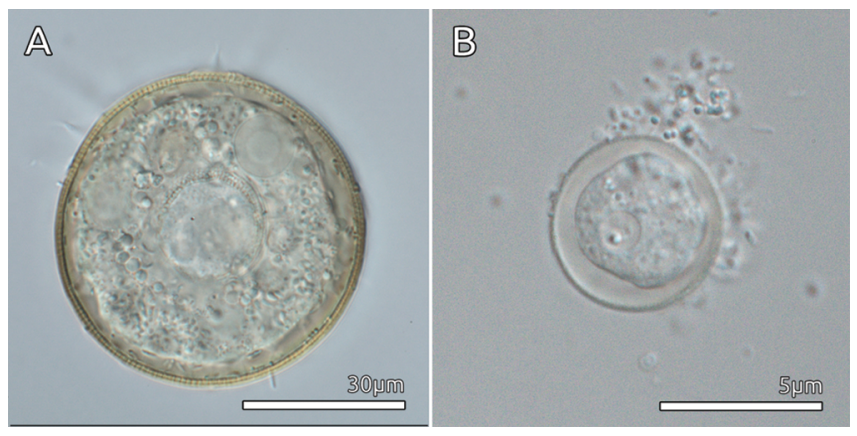

Fig. 1. Species used in this study. A - Arcella intermedia LEP isolate 6 , magnification $630 \times . \mathrm{B}-$ Pyxidicula operculata LEP isolate 1 , magnification $1000 \times$.

standard amoeba culture media, which consists of a $12.5 \mathrm{ml} \mathrm{me-}$ dia, with $12 \mathrm{ml}$ water obtained from the lake of origin, filtered and autoclaved $+0.5 \mathrm{ml}$ of Cereal Grass Media (Fisher Scientific, cat\# BP9727-500). All culture media from experiments were produced at the same time to standardize the material. The media was never replaced, reflecting a limited nutrient environment.

\section{Single-species experiments}

We experimentally established growth curves of $A$. intermedia and $P$. operculata based on the monospecific cultures. Each monospecific culture had initially 50 clonal cells of either $A$. intermedia or $P$. operculata, and grew until population saturation was reached. Saturation was determined when the number of individuals remained constant for a period longer than the species doubling time, or started to decline. All initial cells were taken from the stock cultures at the beginning of stationary phase. For each species, we made three identical replicates of each monospecific culture, starting with populations derived from stock cultures. We homogenized the culture before each replicate counting. Cells were counted by eye in an inverted microscope. We counted individuals using a random sub-sampling strategy (Supplementary material - S1). This strategy consisted in dividing each culture flask into 90 squares $\left(0.25 \mathrm{~cm}^{2}\right.$ each), out of which 10 random squares (i.e., 10 sub-samples) were chosen each time to count the number of individuals. Each sample was defined as the sum of the cells counted in the 10 squares. The sampling procedure was repeated three times for each culture (i.e., three counting events, resulting in 30 squares counted in total). $P$. operculata monospecific culture counting was performed at $100 \times$ magnification, and $A$. intermedia at $50 \times$ magnification. Cell counts were taken three times a day in regular intervals (every 6 hours, starting at 8 am, skipping the 2 am measure), until the culture reached saturation (carrying capacity).

\section{Single-species model fitting}

We used a state-space model (Hostetler and Chandler 2015) of population dynamics, which allows us to infer the variation in abundance assuming stochastic noise in the culture environment and imperfect detection in cells = counts. In this model, the system dynamics was represented by the following stochastic version of discrete-time logistic equation:

$$
E\left[N_{t+1}\right]=N_{t}+\left(r N_{t}\left(1-\frac{N_{t}}{K}\right)\right) \Delta t
$$

where $E\left[N_{t+1}\right]$ is the expected size of the population in time step $t+1, N t$ is the population size at the previous time step, $r$ is the intrinsic growth rate, $K$ is the carrying capacity and $\Delta t$ the size of time interval between $t$ and $t+1$ in days. In order to include stochastic variation in the population dynamics, population size $N_{t+1}$ follows a Poisson distribution with expected value defined by equation 1 . Thus, for each new time step, the population size is drawn from a Poisson distribution with average taken from the logistic equation $\left(E\left[N_{t+1}\right]\right)$.

The cells counted are actually a sample of the total number of cells in the flask. As we homogenized the cultures before counting, we can assume that the inspected region of the flask is a sample of a population of randomly dispersed cells. Thus, the number of cells on the sampled region also follows a Poisson distribution with expected value:

$$
E\left[n_{t}\right]=\left(\frac{N_{t}}{A}\right) a
$$

where $n_{t}$ is the number of cells in a sample, $N_{t}$ is the population size, $A$ is total culture area and $a$ is the sampled area. This equation gives us simply the density of cells multiplied for the observed area. The model allows for imperfect detection through a parameter $p$, which is of the proportion of cells in the sample that were spotted. Assuming the cell detections are independent from each other, the number of cells observed in each sample follows a binomial distribution, with success probability (i.e., detectability) $p$ and $n_{t}$ independent trials. This way, each cell has the probability $p$ of being detected, and the average number of cells detected in the sample is pnt.

The parameters of the model were estimated with a Bayesian fit with a Markov Chain Monte Carlo (MCMC) in JAGS (Hornik et al. 2003), with the rjags and R2jags packages. Each replicate of the experiments (i.e., three for each species, three samples of cell counts at each $t$ within each replicate) was fitted individually. The prior distributions of the parameters were: $r=\operatorname{lognormal}$ distribution with parameters $\mu=-2 \sigma=2 ; K=$ a uniform distribution between 10 and 100 billion; and $p$ (probability of detecting all cells in the sample) $=$ uniform distribution between 0.9 and 1 . The prior of the carrying capacity $K$ was defined considering that $A$. intermedia (with diameter $57 \mu \mathrm{m}$ ) has a maximum estimated density of 39,188 individuals in $1 \mathrm{~cm}^{2}$; whereas $P$. operculata $(5.3 \mu \mathrm{m}$ diameter) a maximum estimated density of 4,530,000. Thus, a culture flask of $22.5 \mathrm{~cm}^{2}$ accommodates around 0.88 million $A$. intermedia cells and 101.99 million $P$. operculata cells. The prior of $p$ was based on previous knowledge on the maximum proportion of cells that were not detected in this kind of counts by lab staff. For each fit, four MCMC chains were iterated with function jags.parallel of package R2jags (Su and Yajima 2015) for five million of steps, burning length of 2.5 million of steps and thinning interval of 2.500 steps.

\section{Competition experiments}

Competition cultures had initially 50 cells of $A$. intermedia and 50 of $P$. operculata (100 individuals in total), and grew for 11.3 days. We established the time of the competition experiment according to the time of saturation in mono-specific cultures in an attempt to exclude factors related to the deterioration of the culture 
media in the experiment. The individual counting sampling design was the same as the single-species methodology described above, in $100 \times$ magnification. We made seven replicates of the competition experiment.

\section{Competition model fitting}

The model fitting procedure was the same as for the singlespecies model, with each replicate fitted individually. Instead of an underlying logistic model (as in the single-species model), we used the stochastic version of the Lotka-Volterra equation to describe the dynamics of the expected population sizes:

$$
\begin{aligned}
& E\left[A_{t+1}\right]=A_{t}+\left(r_{1} A_{t}\left(1-\frac{A_{t}+\alpha P_{t}}{K_{1}}\right)\right) \Delta t \\
& E\left[P_{t+1}\right]=P_{t}+\left(r_{2} P_{t}\left(1-\frac{P_{t}+\beta A_{t}}{K_{2}}\right)\right) \Delta t
\end{aligned}
$$

where, respectively for $A$. intermedia and $P$. operculata, $E\left[A_{t+1}\right]$ and $E\left[P_{t+1}\right]$ are the expected population sizes at time $t+1$, and $A t$ and $P t$ at $t ; r A$ and $r P$ are the intrinsic growth rates, and $K A$ and $K P$ the carrying capacities. $\Delta t$ is the size of time interval between $t$ and $t+1$ in days; and $\alpha$ and $\beta$ are the competition coefficients, which express the competitive effect of one species on the other, relative to intraspecific competitive effects. As in the logistic model fitted to data from mono-specific experiments, population sizes at each time $t$ follow a Poisson distribution to include stochastic variation in the dynamics. The priors used for the competitive dynamics parameters were based on the posteriori distributions from the single-species models. Thus, $r 1$ and $r 2$ priors were, for each species, a log-normal distribution adjusted to the three posteriori distributions (replicates) adjusted to each monoculture experiments. $K 1$ and $K 2$ priors were an uniform distribution between 1,000 and 35,000, again accordingly to the single-species posterior estimates. Lastly, the competition coefficients priors were lognormal distributions with average corresponding to the cell size ratios between the species and high variances (i.e., less informative a priori).

\section{Predicted model outcomes}

We calculated the posterior populations sizes of each species by simulating the competition dynamics as described by equations $3-4$, with and without stochasticity. We drew the parameter values of the simulations from the posterior distributions estimated by the Bayesian fit. The posteriors of each replicate experiment had equal probability of being sampled, and each sample consisted of a set of parameters of the same realization of the posterior, to keep correlations among parameter values. For each parameter set sampled, we iterated the dynamics over the same step times as those of the experiments. We repeated the simulations 5,000 times to get the distribution of predicted population sizes at each time step.

To analyze the sources of variation in the model outcomes, we used estimated population sizes at the end of the time of the experiments (11.3 days). We obtained these estimates from repeated simulations as described above, but with replicates for each parameter combination drawn from posterior distributions. This simulation design allowed us to partition the total variation in the outcomes of the model in three components: between experiments, between draws from posteriors from each experiment, and residual variance (caused by stochastic variation within each replicate simulation). We calculated these variance components for the proportion of simulations that ended up with both populations larger than zero (that is, probability of coexistence), and for the relative final size of populations (the ratio between each population sizes at the end of the experiment and the sum of the both sizes). The variance components ('repeatabilities', Nakagawa et al. 2017)) were estimated from mixed-effect models for proportions at the link scale with the $\mathrm{R}$ package rptR (Stoffel et al. 2017). Confidence intervals for the repeatabilities were estimated with 200 bootstrap samples, using the same package.

As values of intrinsic growth rates $r$ were one order of magnitude larger in mono-specific experiments (see Results), we used different combinations of posteriors from both classes of experiments to assess the consequences of such difference in comparison to competition experiments. We thus repeated the simulations described above combining posteriors for each species, with 'high' (H) and 'low' (L) mean values of $r$. The posteriors of all monospecific experiments were classified as $\mathrm{H}$, while the posterior of five out seven competition experiments were taken as representative of class L (competition experiments 3 and 5 excluded because of mean $r$ values closer to the pure cultures). The combinations of parameters for each set of simulations was then low $r$ for both species (LL), high $r$ for A. intermedia and low for P. operculata (HL), the opposite (LH) and high $r$ for both species.

\section{RESULTS}

\section{Single-species experiments}

Pyxidiculla operculata maximum number cells in mono-specific culture was consistently higher than A. intermedia, which reached an average of 168 cells (Standard deviation 2.3 cells) at the sampled area. $P$. operculata reached an average of 509 cells (standard deviation 132.57 cells). Estimations of $K$ parameter were calculated in relation to the total area of the culture, Arcella reached an average $K=1997$ cells $\mathrm{cm}^{-2}$ and Pyxidicula with an average $K=25,108$ cells $\mathrm{cm}^{-2}$ with your three $K$ posterior credibility intervals did not overlap (Fig. 4, upper middle panel). Both species had similar intrinsic growth rates $(r)$ values between an average of 1.37 days $^{-1}$ (standard deviation 0.13 days $^{-1}$ ) for A.intermedia and 1.46 days $^{-1}$ (standard deviation 0.16 days $^{-1}$ ) for $P$. operculata (Fig. 4, upper left panel). However, because of the difference in $K, P$. operculata took longer to reach its carrying capacity (seven days) than $A$. intermedia (five days, Fig. 2). A. intermedia empirical data fitted the logistic growth model better than $P$. operculata (Fig. 2). The logistic model could not predict the peaks in number of $P$. operculata cells recorded between six and seven days (Fig. 2). 


\section{Competition experiments}

The outcomes of competition experiments were markedly more variable than in mono-specific experiments. Mean cell counts at the end of experiments were higher for $P$. operculata in three replicates $(1,3$, and 4$)$ for $A$. intermedia in other three $(5,6$ and 7$)$ and similar in one replicate (2, Fig. 3). Despite such variation, Lotka-Volterra stochastic model provided credibility intervals that encompassed all the population trajectories of the seven replicates of the competition experiment (Fig. 3), showing an accurate fit (although with variable precision). We compared the outcome between the traditional deterministic and the stochastic model used in this work (Supplementary Table S1), and the stochastic model was the only approach where the result of coexistence obtained in the experiments can be recovered in simulations. Also, the maximum number of cells of both species when growing in competition was much lower if compared to the monospecific cultures. A. intermedia reached a maximum of 45 cells recorded (Fig. 3), around 73\% less than the maximum of 168 cells in a sample reached in mono-specific culture (Fig. 2). Pyxidicula operculata reached a maximum of 114 , almost $80 \%$ less than the maximum of 509 cells in a sample reached in mono-specific culture.

Population sizes at the end of competition experiments were well below their carrying capacities in mono-especific cultures (Fig. 3), which caused considerable uncertainty on the estimates of $K$ values for both species in these experiments (Fig. 4). On the other hand, estimates of intrinsic growth rates $r$ were as precise as those obtained from mono-specific cultures, but about one order of magnitude smaller (average 0.13 and 0.4, standard deviation 0.07 and 0.64 , for Arcella and Pyxidicula respectively). Posteriors of $r$ for both species in competition had a median $r$ around ten to five times smaller than, and no overlap to, the posteriors of $r$ from mono-specific experiments (Fig. 4). Experiment 3 was the exception, as estimated $r$ values for P. operculata reached the same magnitude of mono-specific cultures $(r=1.82)$. The posterior distributions of $r$ estimates for $P$. operculata showed more variation compared to $A$. intermedia. Thus, the experiments in which $P$. operculata grew faster (higher $r$ ) also showed larger $r$ estimates in the end of competition experiment (Experiments 1, 3 and 4, Fig. 4). When A. intermedia stabilizes in values smaller than $P$. operculata (Experiments 3 and 4, Fig. 3), values of $r$ were smaller than the others.

The competition coefficients were estimated with reasonable margin of uncertainty but were compatible with the relative size of the species (Fig. 4). A. intermedia coefficient on $P$. operculata range from units (0.94) to tens (14.1), whereas the competitive coefficients that express the effect of $P$. operculata on $A$. intermedia is in average 0.21 with a standard deviation of 0.15 . The posterior distributions for these coefficients are very similar among replicates, again with the exception of Experiment 3, in which the effect of $A$. intermedia on $P$. operculata was considerably higher than in other experiments.

\section{Predicted model outcomes}

Coexistence probabilities at the time scale of the competition experiments is close to one if at least one of the species had low values of $r$ (Table 1), as estimated for replicates 1-2 and 5-7 (Fig. 4). Moreover, the model estimates that coexistence probabilities would be halved if the two species had the higher intrinsic growth rates estimated from the mono-specific experiments, because the probability of persistence of $A$. intermedia drops from nearly one to 0.43 (Table 1 ).

Coexistence probabilities estimated from the whole set of replicates of competition experiments ranged from almost one to 0.43 , with a mean value of 0.83 . The main source of this variation was differences between simulations ran with the same parameter values (residual variance). This component accounted for $93.2 \%$ of all variation in simulated coexistence probabilities (Table 2), and is caused by the stochastic fluctuations in the dynamic as depicted by the model.

Pyxidicula operculata accounted for 3\% to $94 \%$ of the total cell counts at the end of competition experiments (minimum and maximum from replicates 7 and 4 , respectively). These relative observed abundances had a variance of 4.13 in logistic scale, which is compatible with the between-replicates posterior variances of the relative population size of $P$. operculata (4.33, 95\% credibility interval: $0.94-8.89)$. Differences between replicate experiments accounted for $43 \%$ of the total posterior variance in relative abundances, while within-replicate stochasticity (residual variance) accounted for $52 \%$ (Table 2). The small remaining share of total variance $(0.5 \%)$ was accounted by uncertainty in parameter estimates, expressed by differences between simulations ran with different draws from each posterior distribution. 


\section{P. operculata}
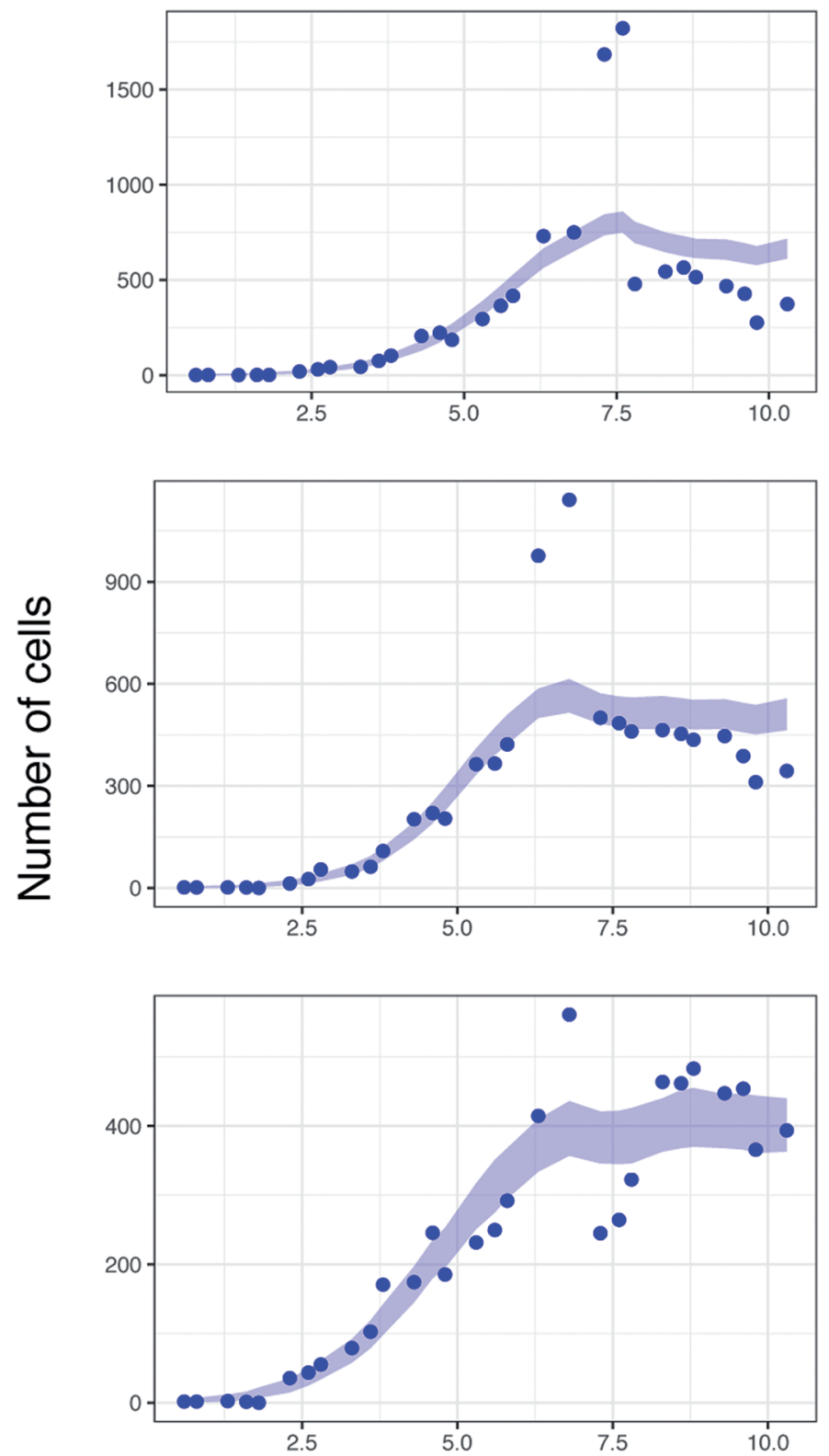

\section{A. intermedia}
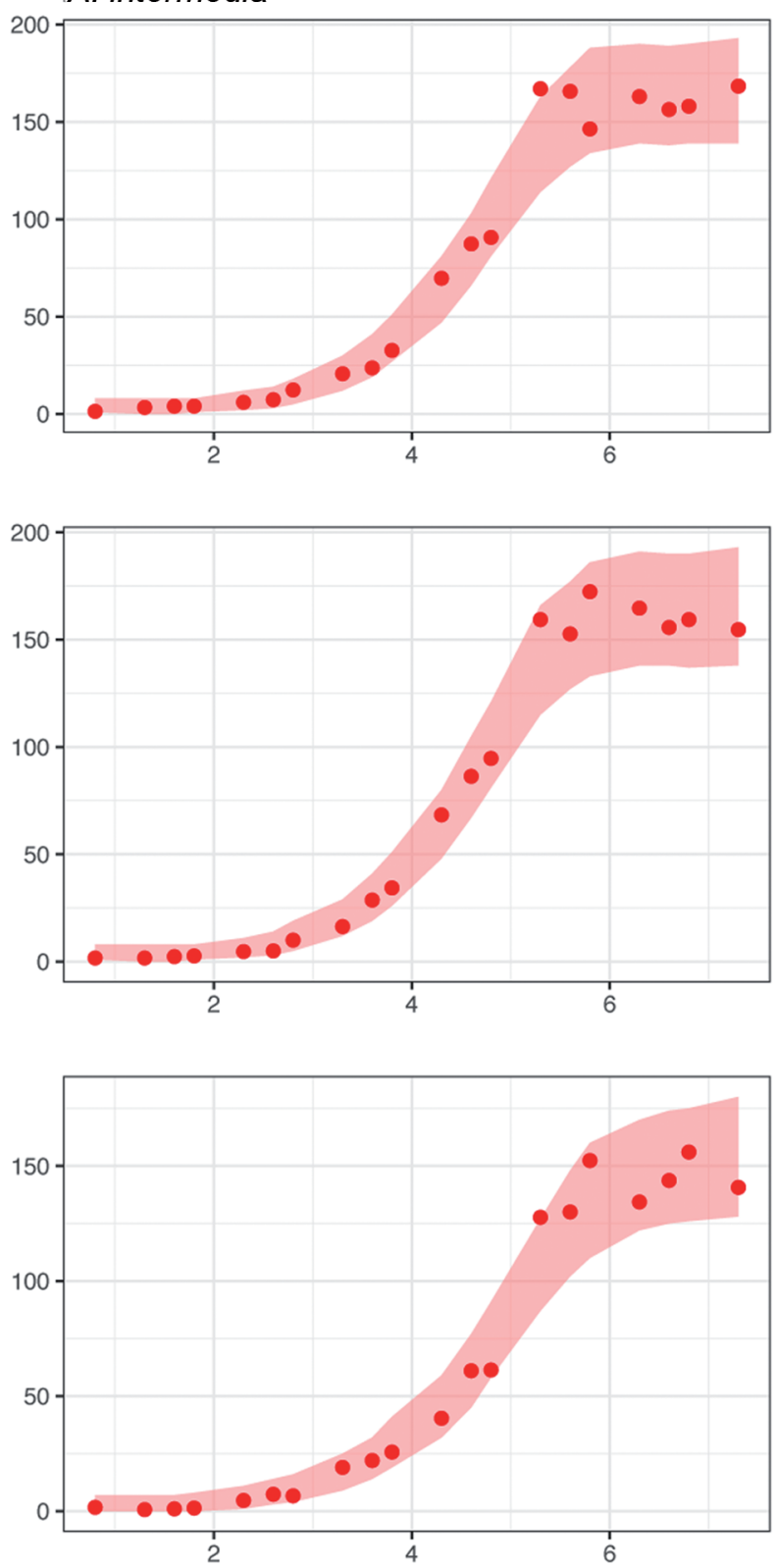

\section{Time (days)}

Fig. 2. Growth curves of Arcella intermedia and Pyxidicula operculata in the monospecific culture experiments (three replicates each). Dots represent the raw sampled data; colored intervals represent the $95 \%$ credibility intervals of cell counts from the Bayesian model fitting.

Fig. 3. Growth curves of Arcella intermedia (in red) and Pyxidicula operculata (in blue) in the competition experiments (seven replicates). Dots represent the raw sampled data, and the colored intervals represent the $95 \%$ credibility intervals of cell counts over time, from the Bayesian fitting. 


\section{Experiment \#1}

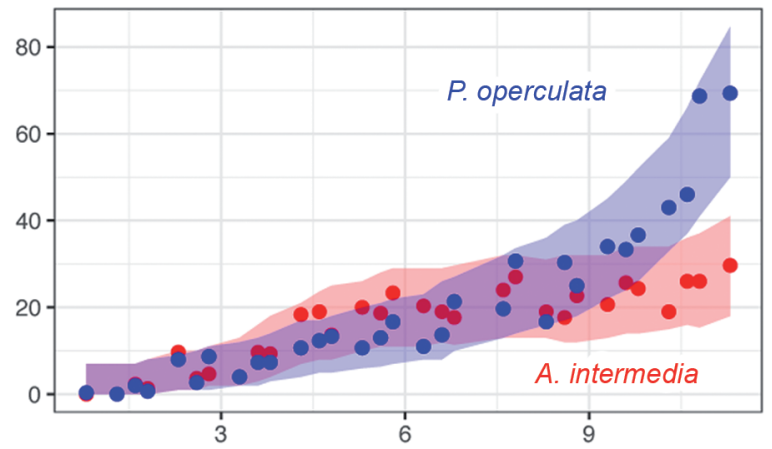

Experiment \#3

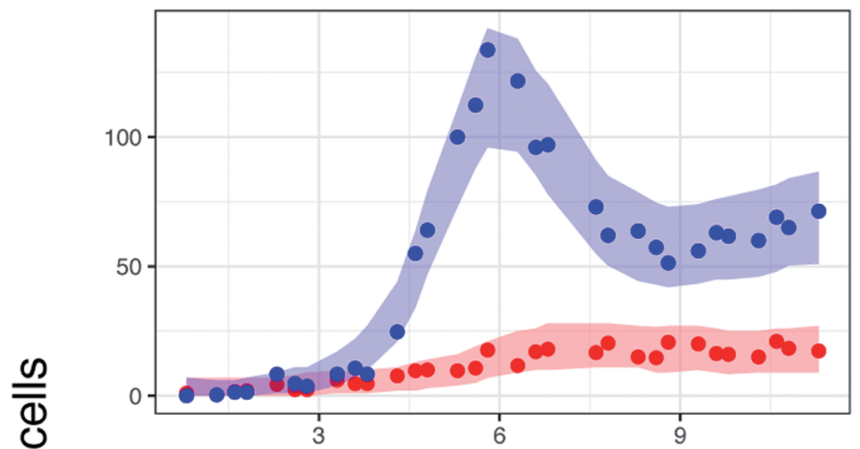

흘

\section{Experiment \#5}

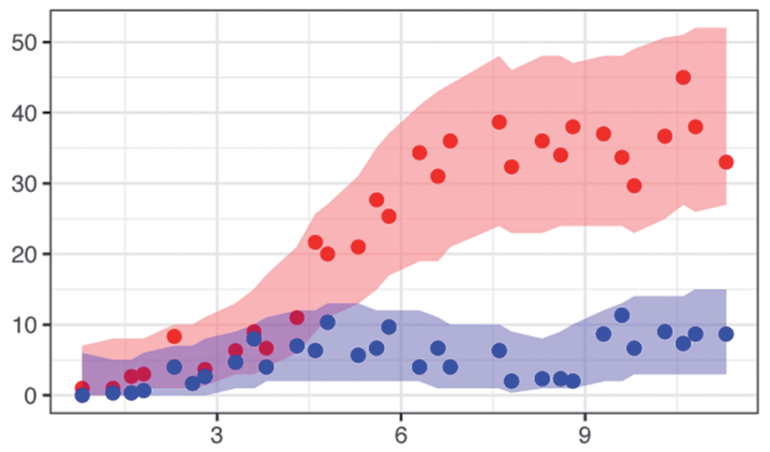

\section{Experiment \#7}

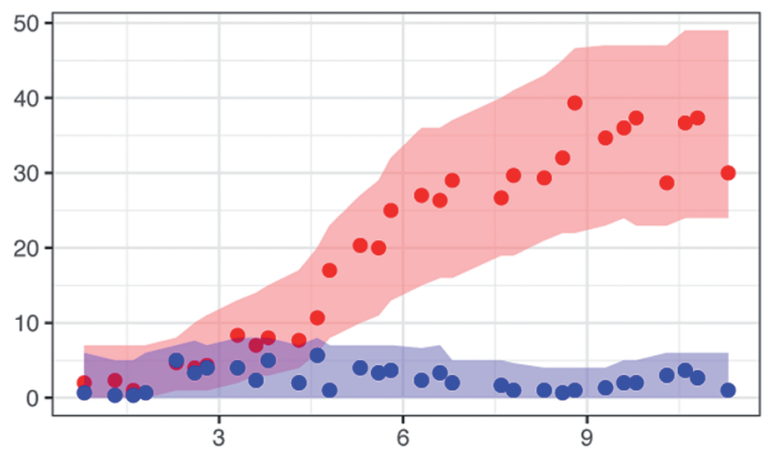

\section{Experiment \#2}

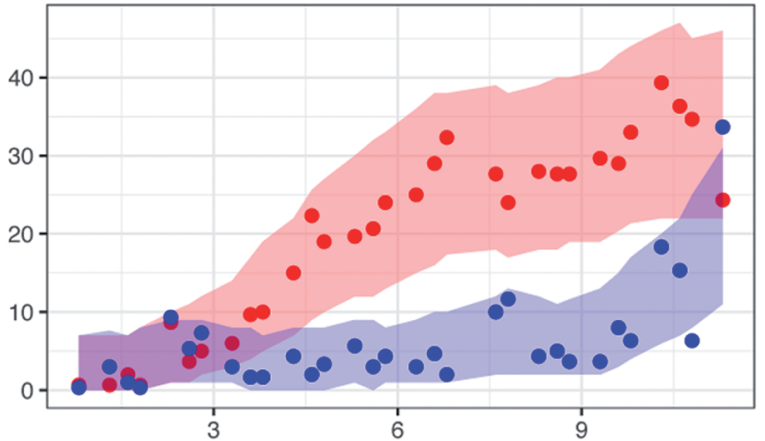

Experiment \#4

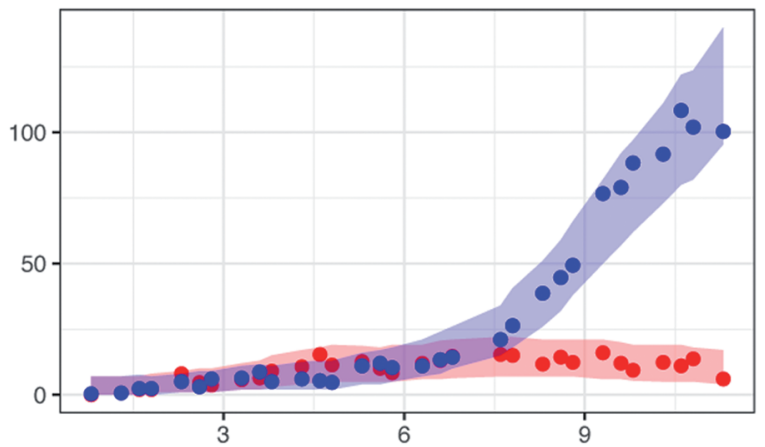

\section{Experiment \#6}

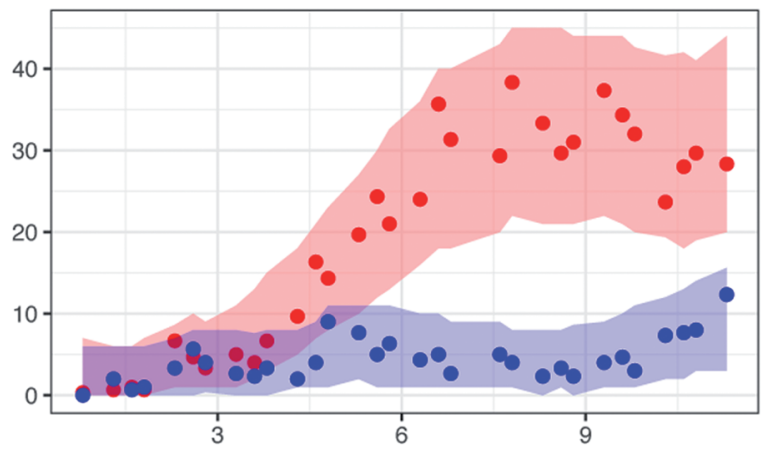

Time (days) 
Table 1. Posterior probabilities of coexistence and of population persistence of each species. Probabilities calculated from simulations of the competition dynamics ran for the extent of the experiments (11.3 days), for the following scenarios: LL: both species with low growth rate $(r)$; HH: both species with high $r$; LH: A. intermedia with low $r$ and $P$. operculata with high $r$; HL: A. intermedia with high $r$ and $P$. operculata with low $r$.

\begin{tabular}{llll}
\hline Scenario & Coexistence & A.intermedia & P. operculata \\
\hline LL & 0.979 & 0.987 & 0.992 \\
HH & 0.430 & 0.431 & 0.999 \\
LH & 0.959 & 0.959 & 1.000 \\
HL & 0.979 & 1.000 & 0.979 \\
\hline
\end{tabular}

Table 2. Variability components of expected probability of coexistence and relative population sizes at the end of the competition experiments. Both outcomes were calculated from repeated simulations of models using parameters taken from posterior distributions for each replicate of the competition experiments (Fig. 4). The values in bold are the proportion of the total variation that is attributable to differences among replicates, among model parameter uncertainty within the same replicate (variation of posterior distributions of parameters) and among simulations with the same set of parameter values (stochastic variation of the modeled dynamics). Values in brackets are $95 \%$ bootstrap confidence intervals.

\begin{tabular}{lll}
\hline Source & $\begin{array}{l}\text { Coexistence } \\
\text { probability }\end{array}$ & $\begin{array}{l}\text { Relative } \\
\text { population sizes }\end{array}$ \\
\hline $\begin{array}{l}\text { Replicate } \\
\text { Parameter } \\
\text { uncertainty }\end{array}$ & $\mathbf{0 . 0 4 9}(0.005-0.117)$ & $\mathbf{0 . 4 3 1}(0.130-0.613)$ \\
Residual & $\mathbf{0 . 0 1 9}(0.005-0.036)$ & $\mathbf{0 . 0 0 5}(0.029-0.077)$ \\
\hline
\end{tabular}

\section{DISCUSSION}

The literature is replete with models and ideas about the maintenance of species diversity (Chesson 2000). The general conclusion achieved was that when the very limiting assumptions of the competitive exclusion principle are met (competition occurs in a stable uniform environment, for the same limiting resource at the same time, and equilibrium is achieved), competitive exclusion must occur (Huston 1979). With all this assumptions it seems likely that complete exclusion rarely occurs in nature. The results presented in this work suggest that for Arcella intermedia and Pyxidicula operculata coexistence is probably maintained in a short term.

We demonstrated that Arcella intermedia and Pyxidicula operculata had a very similar maximum rate of growth in mono-specific culture (Fig. 4). A canonical assumption in population ecology is the correlation of intrinsic rate of population growth and the carrying capacity ( $\max , K)$ with body size (Fenchel 1974). Maximum intrinsic growth rates are thought to be influenced not only by body size but also by temperature. Our experiments had controlled temperature, making body size the only factor influencing growth rate. As the species growth curve didn't have any difference in growth rates, probably some physiological constraint is making growth rates similar or the ten fold difference in size of this organisms is not enough to generate an effect (Fenchel 1974, Giometto et al. 2013). It is noteworthy here that $P$. operculata had a peak of growth between day 6 and 7 that we still do not understand. This could be a signature of an accelerated population growth or a time-delay in $P$. operculata, which can generate chaotic dynamics. We highlight that our fitting procedure did not consider this peak to estimate growth parameters.

The outcomes of competition experiments were markedly more variable than mono-specific experiments. Variation in competition outcomes is mostly caused by residual stochastic fluctuations (Table 2). Variable outcomes of competition are probably indicating that there is strong inter-specific interference between the two parts competing (Fox and Smith 1997, Schoener 1976). This interference may fluctuate along the course of the experiment. The nature of this variation may be intrinsic, corresponding to inherent behavioral heterogeneity, as well as extrinsic, resulting from environmental, ecological, spatial or temporal variability. This stochastic variation is much more present in competition system dynamics than in mono-specific experiments (Fig. 4). Recent works highlight that of individual-scale (cell-cell) interactions may induce individual-level heterogeneity in behavior and physiological characteristics (Menden-Deuer and Rowlett, 2014). This unpredictability affects the observed survival of species and relative population sizes after some time competing (Table 2).

At least in three competition experiments, species growth is most likely not yet stabilized (experiments 1, 2 and 4, Fig. 3). In the long term, because we had such chaotic dynamics, one species or another would probably be ruled out. However, in a culture of enrichment, we could not discard the possibility that the result is more related to the depletion of the environment than the interaction between the two species. This is what makes the system comparable to an ephemeral pool, be- 
cause both species, when they are introduced into this enriched environment, should try to grow their best, before depletion of water resources and quality. However, even in this environment with such specificities, both species maintain the reduction of their growth rate in the presence of the other. In order to simulate a longterm condition, a chemostat would be ideal because there is a continuous input of nutrients and a exit to the waste products. In the time of the experiment, coexistence was the only obtained outcome (Fig. 3). Species coexistence under ecological competition is not rare in natural communities (Huang et al. 2016).

For species to coexist under the Lotka-Volterra model, it is assumed that species should carry significant inter-specific differences. That means complete ecological overlap between species is impossible. Our results indicate that two bacterivorous amoeba species, that grow in the same environmental conditions and with the same range of growth rate values can coexist (Fig. 3), a result in line with other studies on different organisms (Griffiths et al. 2015, Huang et al. 2016, Jiang and Morin 2007, Müller et al. 2012, Passarge et al. 2006). This leads to a question of how much ecological overlap can two species tolerate and still coexist. Probably more than we believe so. For example, the number of coexisting planktonic species far exceeds the theoretical expectation based on competition theory, and many extrinsic factors have been suggested to contribute to coexistence (Kokkoris et al. 2002, Menden-Deuer and Rowlett 2014, Müller et al. 2012).

According to the models, our coexistence results are mainly explained by the drop in growth rates (Table 1), and also by variation between experiments (replicates, Table 2). We need to better understand this result, because in the classic Lotka-Volterra model the parameter $r$ would be an intrinsic characteristic of the species, while the environment could more easily change $K$ and even the competition coefficients. Lotka-Volterra model captures the barest essentials of a multi-species system. As with any model, it wasn't designed to incorporate all possible factors, from environmental conditions to auto ecology of species (Kokkoris et al. 2002). If our competition experiments results are incompatible to all possible Lotka-Volterra model predictions we should try to figure out the biological mechanism driving the system dynamics. Experiments (replicates) could be varying because: a) Individuals are not equivalent (intraspecific variability); b) stochastic effects of small populations (Allee effects); c) toxicity of waste products; d) influence of the bacterial community.

\section{Intraspecific variability}

It is known that intraspecific variation might affect the outcome of coexistence among individuals (Hart et al. 2016), because the outcomes of competitions between individuals with variable competitive abilities are unpredictable (Menden-Deuer and Rowlett 2014). While our monospecific culture experiments growth curves showed consistent results when starting with 50 cells, we have also experimented starting cultures from single cells (Supplementary material S4). In this case growth curves are different among replicates, as observed for other microbial eukaryotes (Mächler and Altermatt 2012). In nature, this variability can be observed as niche differentiation, variability in environmental factors, and variability of individual behavior and/or physiology. For example, species that seem generalists are actually composed of relatively specialized individuals, including algae (Michod 2007), bacteria (Craig MacLean et al. 2005) and even macroorganisms like fish (Svanback and Bolnick 2007). Individual variation, especially for resource use, could interfere with the outcome of competition (Hart et al. 2016). Independently of which factor is causing within population variation, in cases where different competitive abilities are present in a population, even small population sizes or species with inferior competitive ability can survive (Menden-Deuer and Rowlett 2014).

\section{Small population and stochastic effects}

Stochastic effects of small populations at the beginning of the experiment may have a strong influence on the final outcome. $P$. operculata generally survived the competition experiment, but its population growth was certainly impaired (3). P. operculata may be more prone to Allee effects than A. intermedia. Allee effects are defined as a positive correlation between population density and individual fitness, leading to reduced mean fitness in small population densities, possibly due to either reduced social interactions or reduced mating opportunities (Fronhofer et al. 2015). It was previously demonstrated that unicellular organisms can communicate by chemical signaling. Bacteria use quorum sensing communication (Nealson and Hastings 1979, Waters and Bassler 2005) to synchronize the activities of large groups of cells. In Amoebozoa, Dictyostelium discoideum uses cAMP signaling to attract neighbor cells to a central location (Gerisch et al. 1975, Konijn et al. 1967, Loomis 2014). These communication processes seems to be beneficial only with a large number of in- 

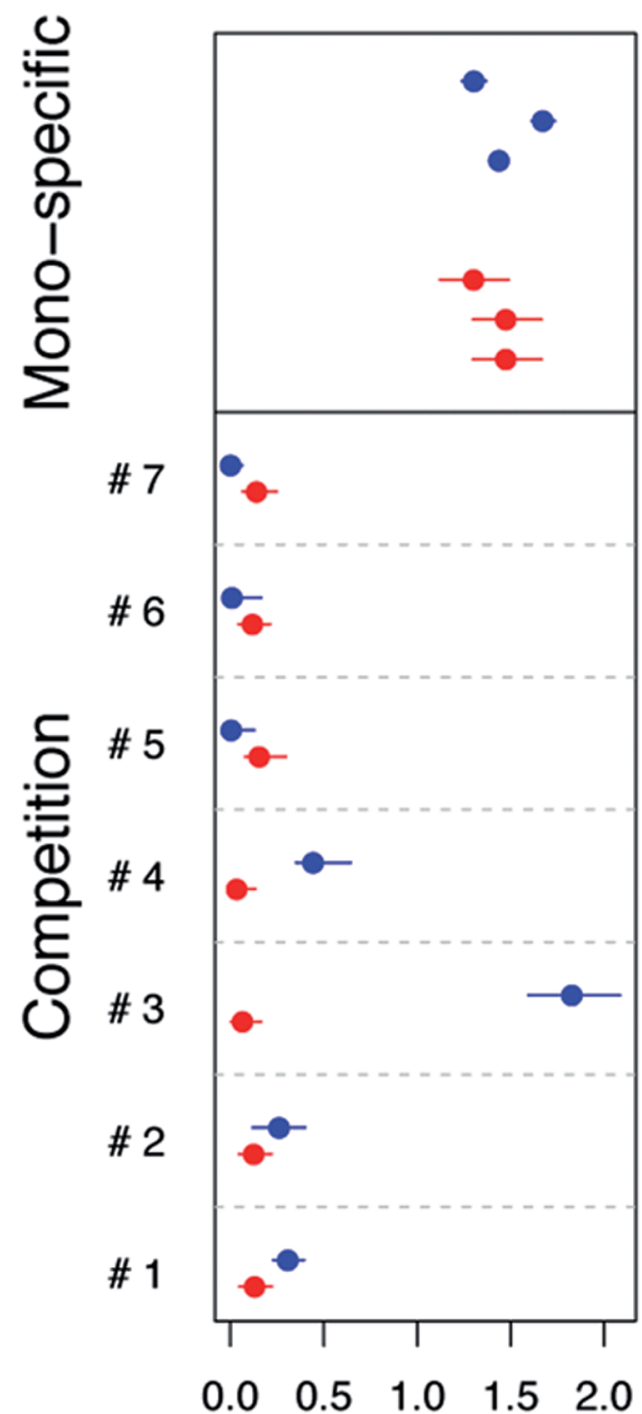

Intrinsic growth ratio (r)
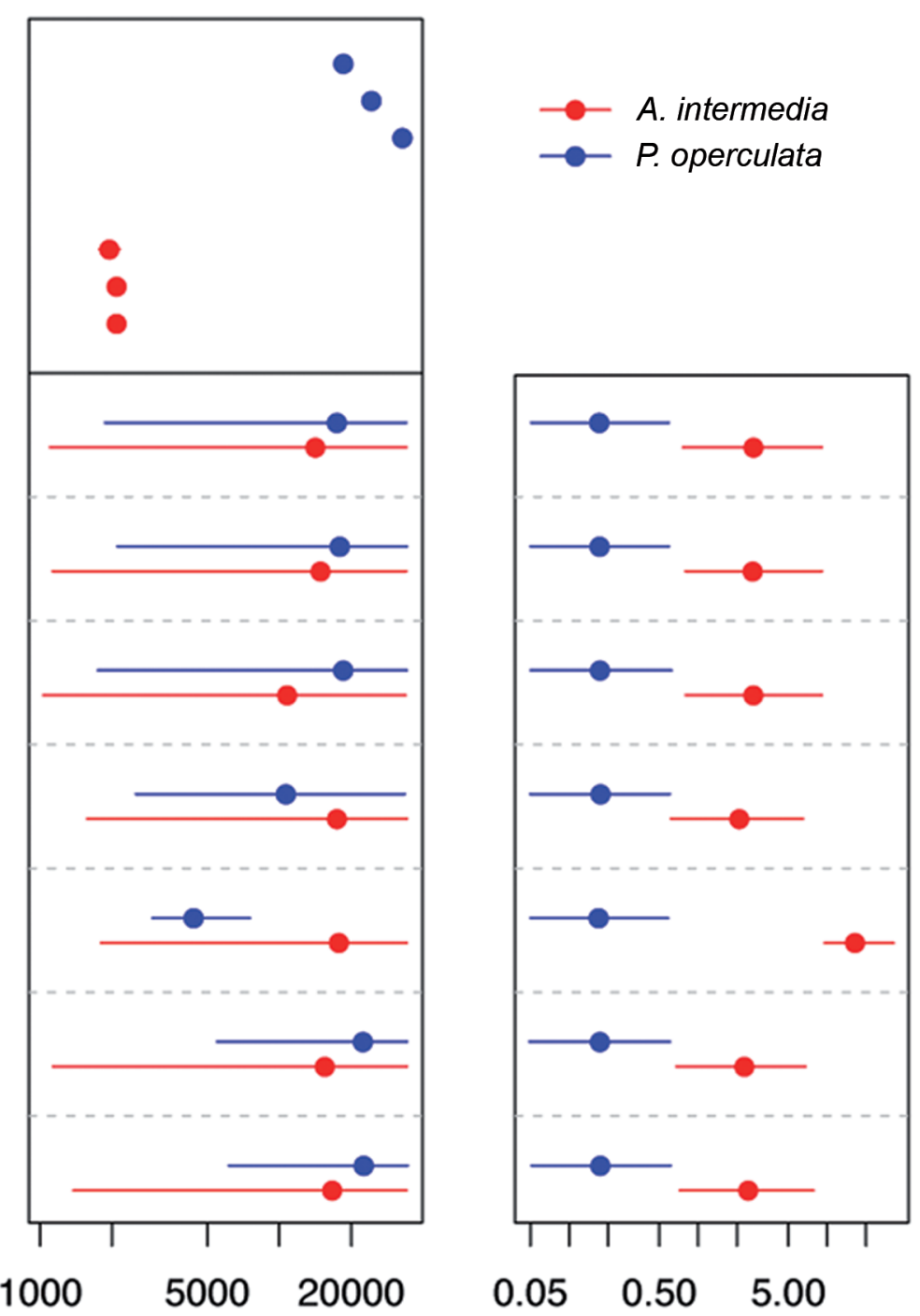

Competition coefficients

Fig. 4. Posterior estimates of the parameters of models fitted to cell counts in each culture. Each panel shows the medians (dots) and $95 \%$ credibility intervals (lines) of posterior distributions of one parameter of the models fitted to data from a replicate (seven for the competition cultures in lower part and three for mono-specific cultures in the upper part). In red, estimates for Arcella intermedia and in blue estimates for Pyxidicula operculata. The values of $K$ are in $\mathrm{cm}^{-2}, r$ are in days ${ }^{-1}$. The competition coefficients are $\alpha$ (red) and $\beta$ (blue) of Eqs. 3-4.

dividuals (Waters and Bassler 2005). If individuals are spread out in wide spaces, traveling to find a partner is a bigger cost.

Stochastic drift processes were expected to affect both species equally, since they started the competition experiments with the same number of individuals. However, the initial densities varying in orders of mag- nitude relatively to species cell size and $K$ (Altermatt et al. 2015). When density relative to the species $K$ is too low, effects of small populations or Allee effects might be more pronounced (Fronhofer et al. 2015). A. intermedia starts the experiment with $3 \%$ of its carrying capacity whereas $P$. operculata starts with only $1 \%$. $P$. operculata has a longer lag phase, which could also 
be an evidence of recovery from Alle effects (Kanarek and Webb 2010). Our competition model does not take into account these types of density effects.

\section{Toxicity of waste products}

Growth limitation of organisms in batch cultures is mainly related to depletion of metabolic substrates or to the accumulation of toxic inhibitors like waste products (Beyers and Odum 2012, Duval et al. 1992). Metabolic waste byproducts can affect the $\mathrm{pH}$ of the environment, and $\mathrm{pH}$ lower than 6.8 was demonstrated to have an inhibitory effect on cell growth (Weisse and Stadler 2006). Some waste products could either participate in enzymatic reactions and displace equilibrium or interact with regulatory sites of enzymes (Castilho et al. 2008). Increased relative resistance to accumulation of waste products may benefit a given species in competition as demonstrated for dinoflagellate species (Kayser 1979). Moreover, species could evolve to use waste products of other, and establish a new equilibrium state different than when in mono specific culture and thereby reducing the strength of negative interactions between species (Barraclough 2015).

\section{Influence of the bacterial community}

Prey richness, predator biomass production (i.e., cell numbers) and diversity are correlated (Saleem et al. 2013). In general, prey richness has a positive effect in predator production because predators can nutritionally benefit from higher prey diversity. However, in a multiple predation system (i.e. more than one species of predator) an increase in prey diversity may have a stabilizing effect in predator production (Saleem et al. 2013). The possible mechanism is that higher prey diversity allows niche complementarity among predators according to their feeding modes, and hence, could reduce competition among predators and allow coexistence. The bacterial communities in this experiment are unknown, but probably quite diverse (Lymperopoulou et al. 2012). In the case of our experiments, the bacterial communities should be similar between replicates in the beginning because the initial conditions are identical, and all amoeba lineages are clonal. However along the time of the experiment this community might be changing. Molecular tools revealed that bacterial community on the environment is orders of magnitude larger than ever thought (López-García and Moreira 2008). Even if the expectation in laboratory conditions is that a few, perhaps opportunistic, lineages became dominant and excluded the rest of the native microbial diversity, the remaining bacterial community is still diverse (Couradeau et al. 2011). Given that $A$. intermedia and $P$. operculata probably generalists, they might be using complementary dimensions of the niche space.

\section{CONCLUSIONS}

Our approaches assess dynamics of single-species growth, and make an initial effort to understand competition between ecologically similar species with a ten-fold difference in diameter. Surprisingly, despite cell-size differences, A. intermedia and $P$. operculata showed the same estimated growth rate in monospecific culture conditions, but different carrying capacities. Either a physiological constraint is making growth rates similar, or the ten-fold difference in size of these organisms is not enough to generate an effect in growth rates. In addition the peak in $P$. operculata growth could be a signal of small population effects having a strong influence in growth, thus even in monospecific culture P.operculata may not grow to their full potential.

Our competition experiments always resulted in coexistence, despite predictions to the contrary. Our deterministic models always predict the exclusion of one of the species in equilibrium. In 11.3 days, coexistence always happened and in 30 days it is still the most-likely outcome, which suggests that coexistence is a very long-lasting transient. In the very long term, because of chaotic dynamics, one species or another would probably be ruled out. Maybe the context of coexistence at situations with ephemeral resources can explain this result, where a variable source of disturbances can promote coexistence of organisms (Huston 1979). We expected to see both species growing to the full potential in order to take advantage of the resource availability. However, what we actually see experimentally is both species reducing their abundances and growth rates in combined cultures. Additionally the outcome of competition is highly variable, although all experiments ended in coexistence. All experiments started with the exact same conditions, and yet, the largest source of variation was due to stochasticity. We propose four main explanations for the variation observed: i) individuals are not equivalent (even when clonal); ii) stochastic effects of small populations (Allee effects); iii) toxicity of waste products; and iv) influence of the bacterial community. All these sources of variation may interact with experiments differentially along the course of the experiment, but also differently between replicates. 
Data accessibility: Supporting Figures are available in supplementary material. Raw data and codes used for analysis are available in https://github. com/GiuliaRibeiro/suppCompetition.

Authors contributions: G. M. R. and D. L. conceived the study and methodology of investigation. G. M. R., S. P. J and A. P. S. conducted experimental laboratory work. P. I. P. and R. M. C. conducted data analysis with input of M. C. R., G. M. R. and D. L. drafted the manuscript with input of M. C. R., P. I. P., R. M. C. and A. P. S. All authors gave final approval for publication.

Competing interests: We declare we have no competing interests.

Acknowledgments: We thank Daniel Alcântara for the help with the cell counting procedures during the experimental phase of this work. Funding for this work was provided by FAPESP fellowships to DJGL (\#2013/04585); GMR (\#2015/02689-1); RMC (\#2014/23497-0); APS (\#2013/25729-3), PIP (\# 2013/19250-7) and a PUB-USP fellowship to SPJ (\#1217).

\section{REFERENCES}

Altermatt F., Bieger A., Carrara F., Rinaldo A., and Holyoak M. (2011) Effects of connectivity and recurrent local disturbances on community structure and population density in experimental metacommunities. PLoS One 6: e19525

Altermatt F., Fronhofer E. A., Garnier A., Giometto A., Hammes F., Klecka J., Legrand D., Maechler E., Massie T. M., Pennekamp F. et al. (2015) Big answers from small worlds: a user's guide for protist microcosms as a model system in ecology and evolution. Methods Ecol. Evol. 6: 218-231

Amarasekare P. (2000) The geometry of coexistence. Biol. J. Linn. Soc. 71: 1-31

Barraclough T. G. (2015) How do species interactions affect evolutionary dynamics across whole communities? Annu. Rev. Ecol. Evol. Syst. 46: 25-48

Bastolla U., Lassig M., Manrubia S. C., and Valleriani A. (2005). Biodiversity in model ecosystems, I: coexistence conditions for competing species. J. Theor. Biol. 235: 521-530

Beyers R. J. and Odum H. T. (2012) Ecological microcosms. SSBM

Cadotte M. W. (2007) Competition-colonization trade-offs and disturbance effects at multiple scales. Ecology 88: 823-829

Cadotte M. W., Mai D. V., Jantz S., Collins M. D., Keele M., and Drake J. A. (2006) On testing the competition-colonization trade-off in a multispecies assemblage. Am. Nat. 168: 704-709

Carrara F., Altermatt F., Rodriguez-Iturbe I., and Rinaldo A. (2012) Dendritic connectivity controls biodiversity patterns in experimental metacommunities. PNAS 109: 5761-5766

Castilho L., Moraes A., Augusto E., and Butler M. (2008) Animal cell technology: from biopharmaceuticals to gene therapy. Garland Science

Chesson P. (2000) Mechanisms of maintenance of species diversity. Annu. Rev. Ecol. Syst. 31: 343-366

Couradeau E., Benzerara K., Moreira D., Gerard E., Kázmierczak J., Tavera R., and Lóopés-García P. (2011) Prokaryotic and eukaryotic community structure in field and cultured microbialites from the alkaline lake Alchichica (Mexico). PLoS One 6: e28767

Craig MacLean R., Dickson A., and Bell G. (2005) Resource competition and adaptive radiation in a microbial microcosm. Ecol. Lett. 8: $38-46$
DeLong J. P., Okie J. G., Moses M. E., Sibly R. M., and Brown J. H. (2010) Shifts in metabolic scaling, production, and efficiency across major evolutionary transitions of life. PNAS 107: 12941-12945

Duval D., Demangel C., Miossec S., and Geahel I. (1992) Role of metabolic waste products in the control of cell proliferation and antibody production by mouse hybridoma cells. Hybridoma 11: 311-322

Fenchel T. (1974) Intrinsic rate of natural increase: the relationship with body size. Oecologia 14: 317-326

Fox J. W. and Smith D. C. (1997) Variable outcomes of protistrotifer competition in laboratory microcosms. Oikos, 489-495

Fronhofer E. A., Klecka J., Melián C. J., and Altermatt F. (2015) Condition-dependent movement and dispersal in experimental metacommunities. Ecol. Lett. 18: 954-963

Gause G. F. (1934) The struggle for existence. Soil Science 41: 159

Gerisch G., Fromm H., Huesgen A., and Wick U. (1975) Control of cell-contact sites by cyclic amp pulses in differentiating Dictyostelium cells. Nature 255: 547

Giometto A., Altermatt F., Carrara F., Maritan A., and Rinaldo A. (2013) Scaling body size fluctuations. PNAS 110: 4646-4650

Giometto A., Rinaldo A., Carrara F., and Altermatt F. (2014) Emerging predictable features of replicated biological invasion fronts. PNAS 111: 297-301

Griffiths J. I., Warren P. H., and Childs D. Z. (2015) Multiple environmental changes interact to modify species dynamics and invasion rates. Oikos 124: 458-468

Haddad N. M., Holyoak M., Mata T. M., Davies K. F., Melbourne B. A., and Preston K. (2008) Species traits predict the effects of disturbance and productivity on diversity. Ecol. Lett. 11: 348-356

Hart S. P., Schreiber S. J., and Levine J. M. (2016) How variation between individuals affects species coexistence. Ecol. Lett. 19: $825-838$

Hornik K., Leisch F., and Zeileis A. (2003) Jags: A program for analysis of Bayesian graphical models using Gibbs sampling. $D S C, \mathbf{2}, 1-1$

Hostetler J. A. and Chandler R. B. (2015) Improved state-space models for inference about spatial and temporal variation in abundance from count data. Ecology 96: 1713-1723

Huang W., de Araujo Campos P. R., de Oliveira V. M., and Ferreira F. F. (2016) A resource-based game theoretical approach for the paradox of the plankton. PeerJ 4: e2329

Huete-Ortega M., Cermeño P., Calvo-Díaz A., and Marañón E. (2012) Isometric size-scaling of metabolic rate and the size abundance distribution of phytoplankton. Proc. R. Soc. B 279: $1815-1823$

Huston M. (1979) A general hypothesis of species diversity. Am. Nat. 113: 81-101

Jeremy W., Peter J., et al. (2001) Effects of intra- and interspecific interactions on species responses to environmental change. J. Anim. Ecol. 70: 80-90

Jiang L. and Morin P. J. (2007) Temperature fluctuation facilitates coexistence of competing species in experimental microbial communities. J. Anim. Ecol. 76: 660-668

Kanarek A. R. and Webb C. T. (2010) Allee effects, adaptive evolution, and invasion success. Evol. Appl. 3: 122-135

Kayser H. (1979) Growth interactions between marine dinoflagellates in multi-species culture experiments. Mar. Biol. 52: 357369 
Kempes C. P., Dutkiewicz S., and Follows M. J. (2012) Growth, metabolic partitioning, and the size of microorganisms. PNAS 109: 495-500

Kokkoris G. D., Jansen V. A., Loreau M., and Troumbis A. Y. (2002) Variability in interaction strength and implications for biodiversity. J. Anim. Ecol. 71: 362-371

Konijn T. M., Van De Meene J., Bonner J. T., and Barkley D. S. (1967) The acrasin activity of adenosine-3', 5'-cyclic phosphate. PNAS 58: 1152-1154

Kosakyan A., Gomaa F., Lara E., and Lahr D. J. (2016) Current and future perspectives on the systematics, taxonomy and nomenclature of testate amoebae. Eur. J. Protistol. 55: 105-117

Loomis W. F. (2014) Cell signaling during development of dictyostelium. Dev. Biol. 391: 1-16

López-García P. and Moreira D. (2008) Tracking microbial biodiversity through molecular and genomic ecology. Res. Microbiol. 159: 67-73

Lotka A. J. (1920) Analytical note on certain rhythmic relations in organic systems. PNAS 6: 410-415

Lymperopoulou D. S., Kormas K. A., and Karagouni A. D. (2012) Variability of prokaryotic community structure in a drinking water reservoir (Marathonas, Greece). Microb. Environ. 27: 1-8

Mechler E. and Altermatt F. (2012) Interaction of species traits and environmental disturbance predicts invasion success of aquatic microorganisms. PLoS One 7: e45400

Meisterfeld R. (2000a) Order Arcellinida Kent, 1880. In: An Illustrated Guide to the Protozoa (Eds. J. J. Lee, G. F. Leedale, P. Bradbury). 2nd edition. Society of Protozoologists, Allen Press, Lawrence, Kansas, 827-860

Menden-Deuer S. and Rowlett J. (2014) Many ways to stay in the game: individual variability maintains high biodiversity in planktonic microorganisms. J. R. Soc. Interface 11: 20140031

Michod R. E. (2007) Evolution of individuality during the transition from unicellular to multicellular life. PNAS 104 (suppl 1): 8613-8618

Muller J. P., Hauzy C., and Hulot F. D. (2012) Ingredients for protist coexistence: competition, endosymbiosis and a pinch of biochemical interactions. J. Anim. Ecol. 81: 222-232

Nakagawa S., Johnson P. C., and Schielzeth H. (2017) The coefficient of determination $\mathrm{r} 2$ and intra-class correlation coefficient from generalized linear mixed-effects models revisited and expanded. J. R. Soc. Interface 14: 20170213

Nealson K. and Hastings J. W. (1979) Bacterial bioluminescence: its control and ecological significance. Microbiol. Rev. 43: 496
Passarge J., Hol S., Escher M., and Huisman J. (2006) Competition for nutrients and light: stable coexistence, alternative stable states, or competitive exclusion? Ecol. Monogr. 76: 57-72

Petchey O. L., McPhearson P. T., Casey T. M., and Morin P. J. (1999) Environmental warming alters food-web structure and ecosystem function. Nature 402: 69

Pianka E. R. (2011) Evolutionary ecology. Eric R. Pianka

Rosindell J., Hubbell S. P., and Etienne R. S. (2011) The unified neutral theory of biodiversity and biogeography at age ten. Trends Ecol. Evol. 26: 340-348.

Saleem M., Fetzer I., Harms H., and Chatzinotas A. (2013) Diversity of protists and bacteria determines predation performance and stability. ISME J. 7: 1912

Schoener T. W. (1976) Alternatives to Lotka-Volterra competition: models of intermediate complexity. Theor. Popul. Biol. 10: 309-333

Stoffel M. A., Nakagawa S., and Schielzeth H. (2017) rptr: Repeatability estimation and variance decomposition by generalized linear mixed-effects models. Methods Ecol. Evol. 8: 1639-1644

Su Y.-S. and Yajima M. (2015) R2jags: Using R to Run 'JAGS'. $R$ package version $0.5-7$

Svanback R. and Bolnick D. I. (2007) Intraspecific competition drives increased resource use diversity within a natural population. Proc. R. Soc. B 274: 839-844

Verhulst P. (1845) Recherches mathmatiques sur la loi d'accroissement de la population. Nouv. Mem. Acad. R. Sci. Bruxelles 18: 14-54

Violle C., Pu Z., and Jiang L. (2010) Experimental demonstration of the importance of competition under disturbance. PNAS 107: 12925-12929

Violle C., Nemergut D. R., Pu Z., and Jiang L. (2011) Phylogenetic limiting similarity and competitive exclusion. Ecol. Lett 14: 782-787

Volterra V. (1926) Fluctuations in the abundance of a species considered mathematically. Nature 119: 12

Waters C. M. and Bassler B. L. (2005) Quorum sensing: cell-tocell communication in bacteria. Annu. Rev. Cell Dev. Biol. 21: 319-346

Weisse T. and Stadler P. (2006) Effect of ph on growth, cell volume, and production of freshwater ciliates, and implications for their distribution. Limnol. Oceanogr. 51: 1708-1715

Received on $13^{\text {th }}$ August, 2019; revised on $4^{\text {th }}$ November, 2019; accepted on $4^{\text {th }}$ November, 2019 
SUPPLEMENTARY FIGURES

Experiments are set up in triplicate flasks.

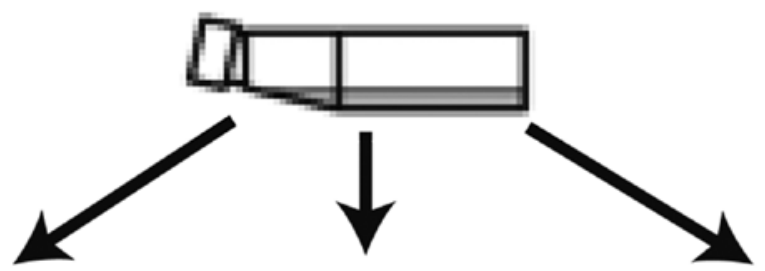

10 squares randomly chosen from the 90 -squared grid, three times independently (replicates).
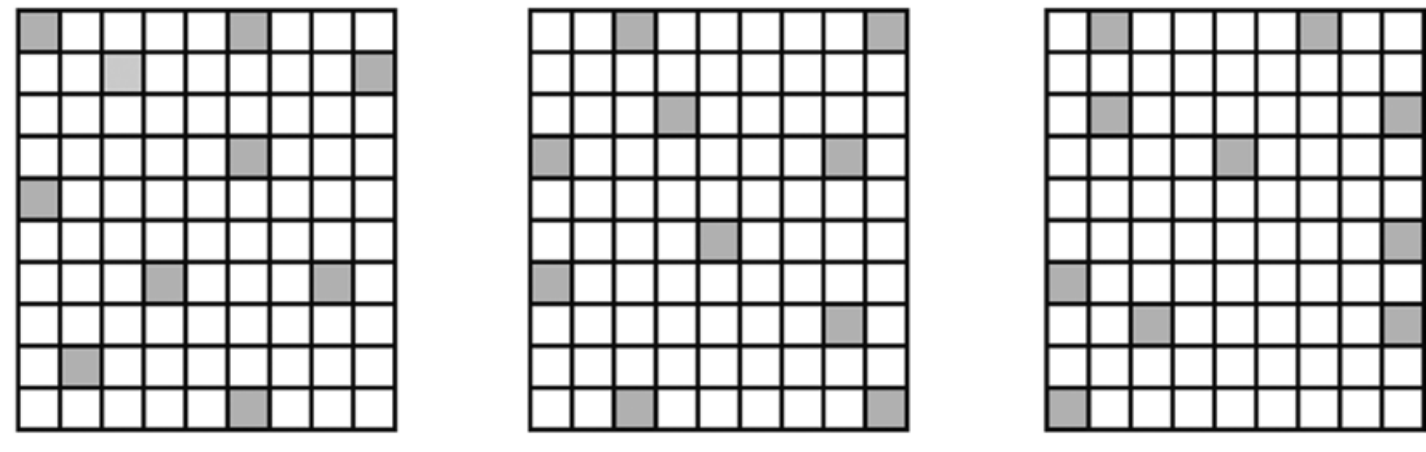

$\overline{0.25} \mathrm{~cm}$

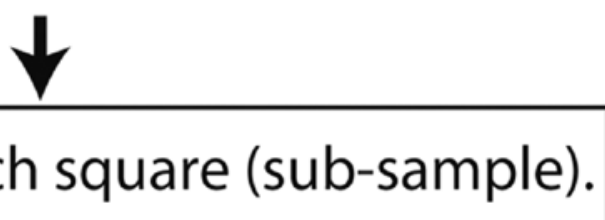

Cells counted in each square (sub-sample).

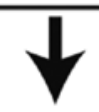

Sample: sum of the 10 sub-samples.

Calculate the average of the three replicates.

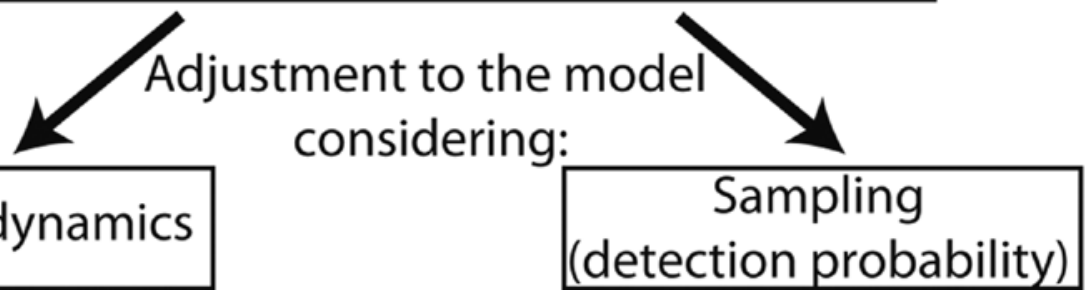

Fig. S1. Overview of data collection design. Microcosms are assembled and sampled by a sub- sampling strategy where the organisms are counted by eye. Model adjustment considers both the system dynamics and the sampling level. 
p

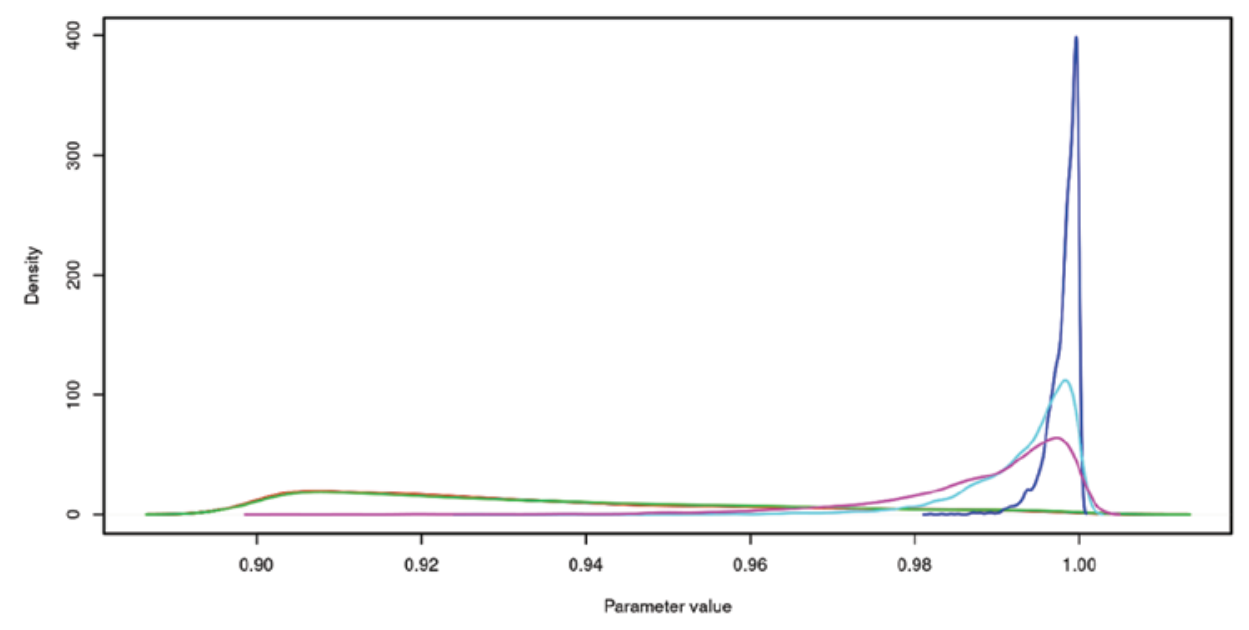

k
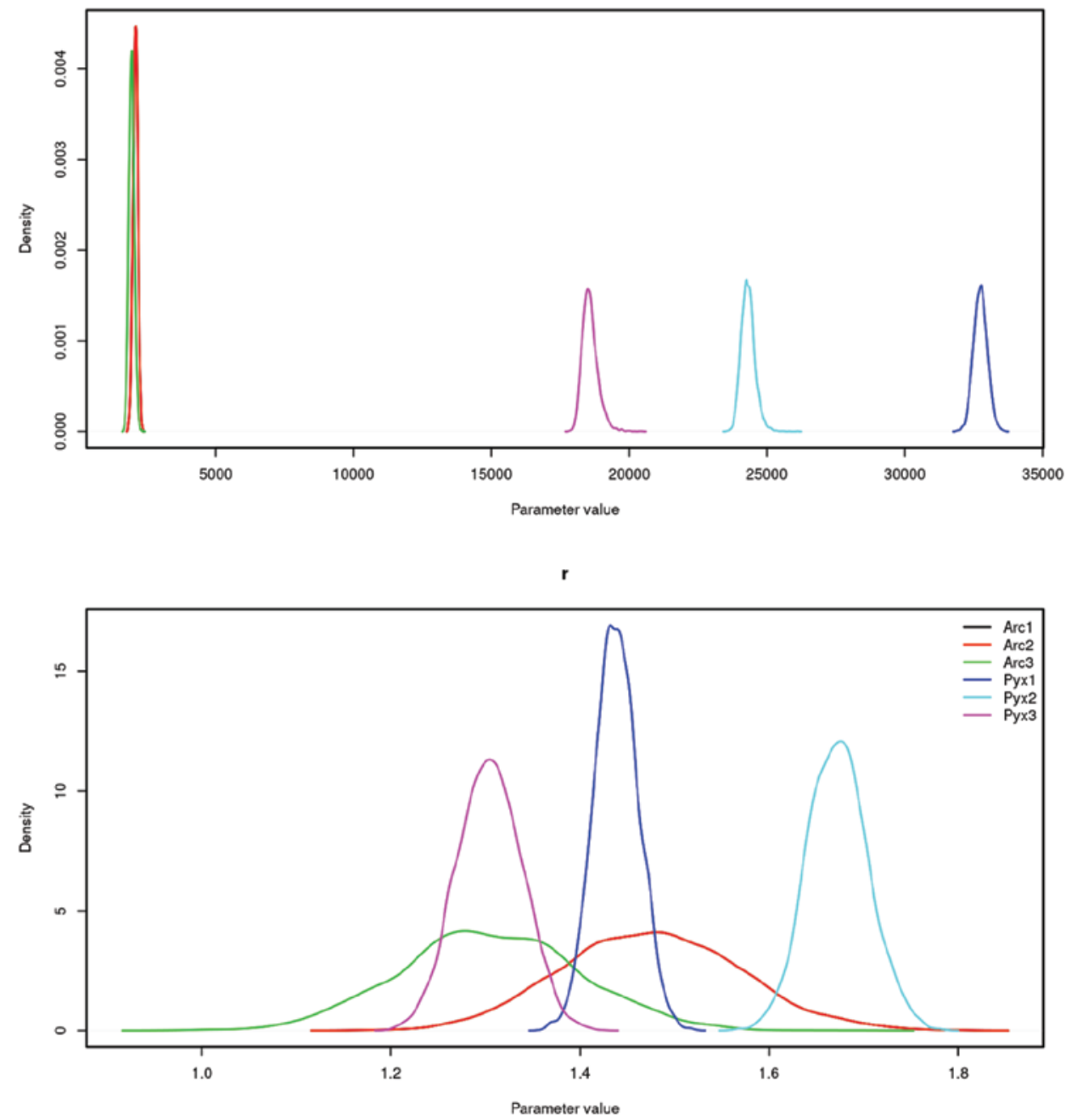

Fig. S2. Posterior distributions of the logistic model parameters. The values of $K$ are in cells $\mathrm{cm}^{-2}, r=\mathrm{d}^{-1}$. $P$ is the detection probability. $P$ has a fixed range between 0.9 and 1 . Color lines represents each one of the single-species experiments, color legend is in the right corner of the figure. A.intermedia experiments are Arc 1, 2 and 3. P.operculata experiments are Pyx 1, 2 and 3. 
kA

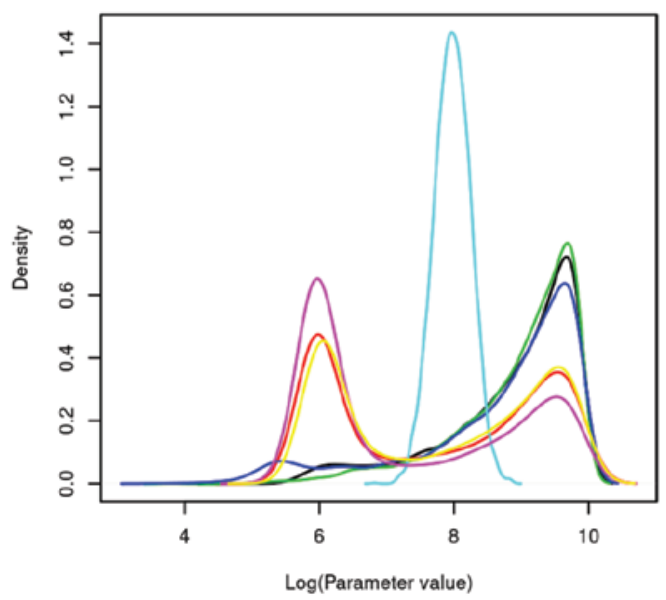

rA

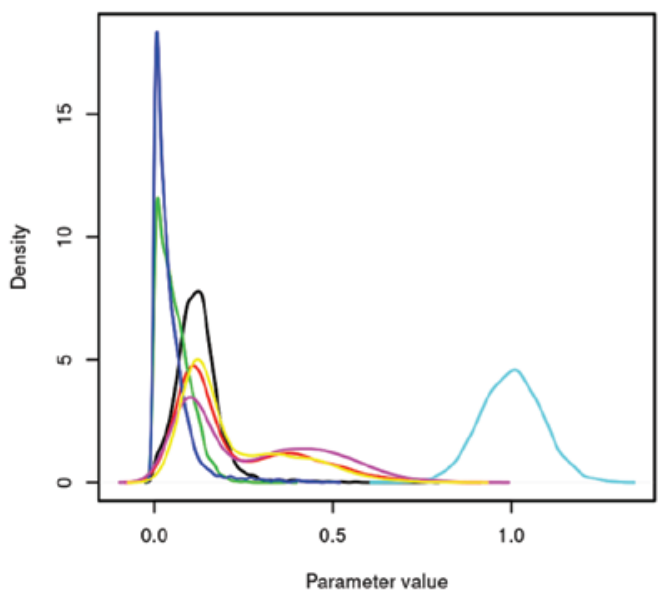

aAP

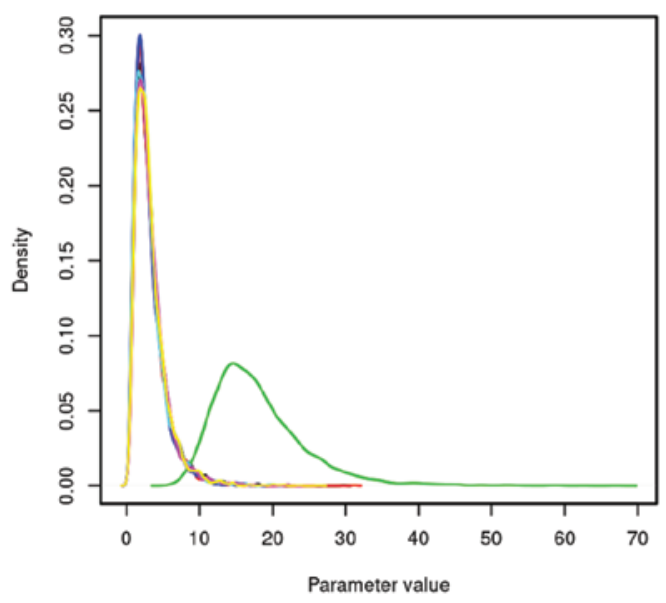

kP

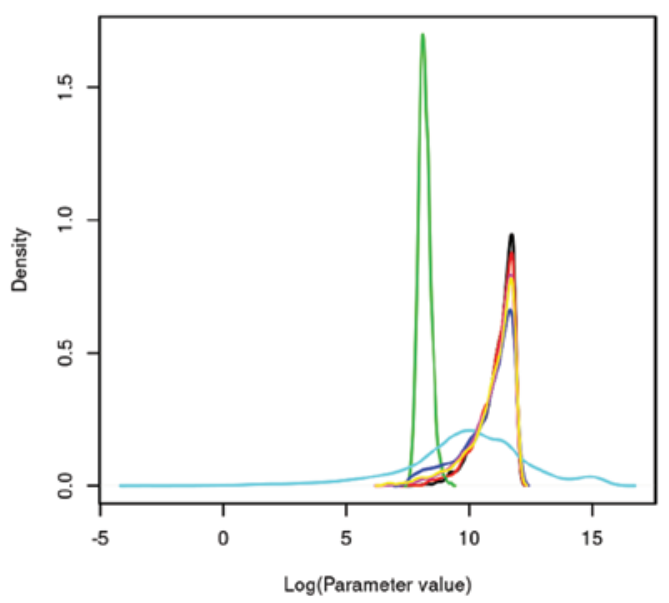

rP

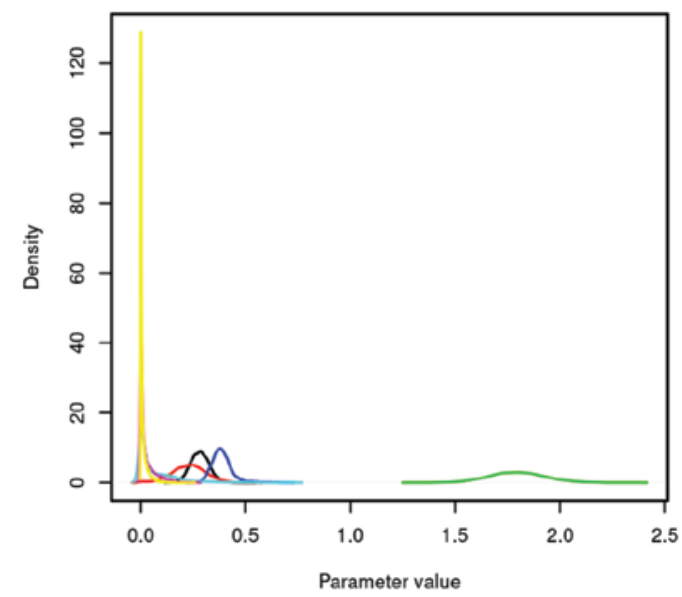

aPA

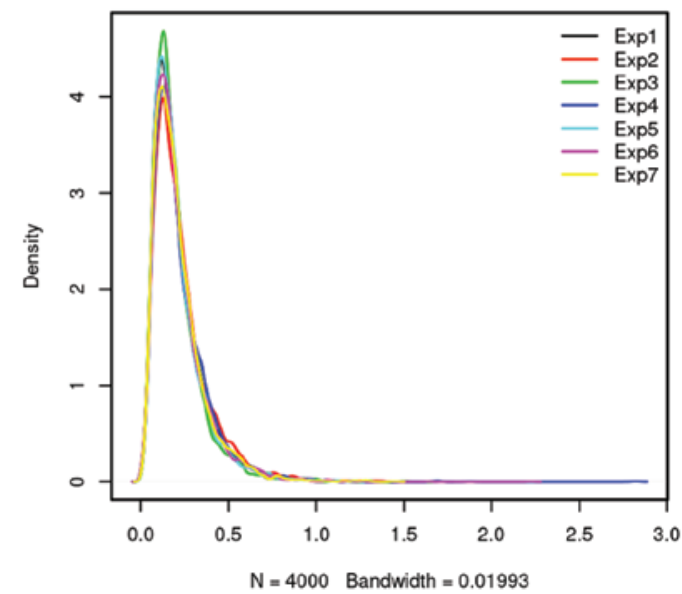

Fig. S3. Posterior distributions of the competition model parameters for the species Arcella intermedia (A) and Pyxidicula operculata (P). Each colored line represent one of the replicates of the competition experiment (color legend shown in the last figure). The values of $k$ are in a logarithmic scale of cells $\mathrm{cm}^{-2}, r$ are in days ${ }^{-1}$. aAP is the competition coefficient of the influence of A species on P (Eq. 3), whereas $a P A$ is the competition coefficient of the influence of $\mathrm{P}$ on $\mathrm{A}$ (Eq. 4). 
Coexistence in an Amoebae Microcosm 233

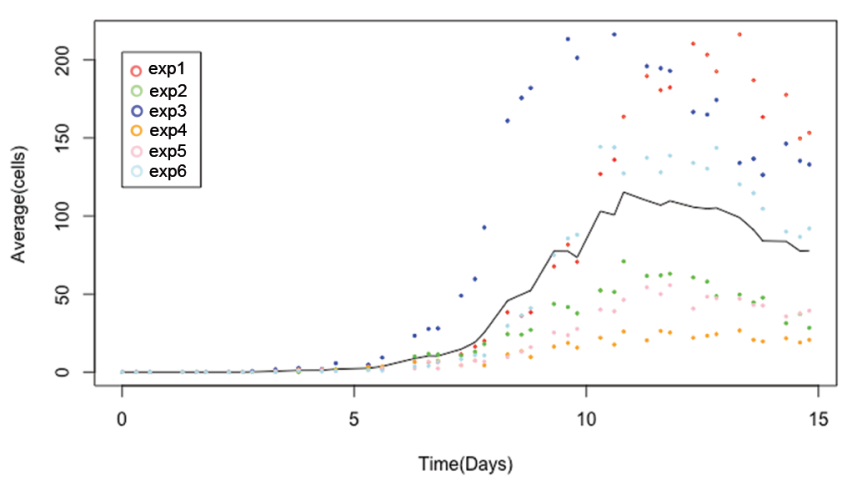

Fig. S4. Growth curves for A.intermedia when started the experiment with a single cell. Color points represents each one of the single-cell experiments, color legend is in the left corner of the figure. Black line correspond to the average growth between experiments.

\section{SUPPLEMENTARY TABLES}

Table S1. Proportion of competition simulations in which population reach the end of 11.3 days with size higher than zero in the deterministic and stochastic models of competition.

Deterministic

\begin{tabular}{lll}
\hline & $\mathrm{N}($ Pyx $)=0$ & $\mathrm{~N}($ Pyx $)>0$ \\
$\mathrm{~N}($ Arc $)=0$ & 0.000 & 0.788 \\
$\mathrm{~N}($ Arc $)>0$ & 0.212 & 0.000
\end{tabular}

Stochastic

\begin{tabular}{lll} 
& $\mathrm{N}(\operatorname{Pyx})=0$ & $\mathrm{~N}($ Pyx $)>0$ \\
$\mathrm{~N}($ Arc $)=0$ & 0.002 & 0.589 \\
$\mathrm{~N}($ Arc $)>0$ & 0.003 & 0.405 \\
\hline
\end{tabular}

